\title{
Texture Formation and Aging Behavior in $18 \%$ Nickel Maraging Steel Cold Rolled and Austenitized by Simulated Continuous Annealing Process*
}

\author{
By Yoshihiro HOSOYA, ${ }^{* *}$ Yoshinobu SHIMA, ${ }^{* * *}$ Tomoyoshi OHKITA ${ }^{* * *}$ \\ and Akihiko NISHIMOTO**
}

\section{Synopsis}

Texture formation and aging behavior in a cold rolled $18 \% \mathrm{Ni}$ maraging steel have been studied to apply a continuous annealing process to austenitization of this type of steel sheet. The results obtained are summarized as follows.

(1) Austenitization of the cold rolled $18 \% \mathrm{Ni}$ maraging steel can be performed in a continuous annealing line to provide the mechanical property comparable to that obtained in the conventional austenitizing condition of $820^{\circ} \mathrm{C} \times 1 \mathrm{~h}$ if the austenitizing temperature is higher than $900^{\circ} \mathrm{C}$.

(2) The $\{111\}\langle u v w\rangle$ orientations, which strongly developed during cold rolling, gradually change into the near (557)[110] and (554) $[\overline{156}]$ orientations and the $(001)[0 \overline{1} 0]$ orientation evolves with progress of austenitizing.

(3) A marked hardness increase of about $40 \%$ from the as-annealed state was observed in the early stage of aging at $480^{\circ} \mathrm{C}$, irrespective of the prior austenitizing conditions.

(4) The number of $\mathrm{Fe}$ atoms with Mo neighbors decreases within 3 min of aging at $480^{\circ} \mathrm{C}$, as evidenced by the Mössbauer spectrometry. The marked hardening in the early stage of aging is suggested to be a result of lattice distortion by clustering of Mo atoms.

\section{Introduction}

On the mechanical properties of $18 \% \mathrm{Ni}$ maraging steels which were introduced as unique ultra high tensile strength steels in 1962,1) a lot of papers have been published for the last two decades. The most of them are the practical studies on improvement of the tensile strength and toughness by alloying of Co, $\mathrm{Ti}$ and $\mathrm{Mo},{ }^{1-6)}$ and the fundamental studies on precipitation mechanism of the intermetallic compounds during aging. ${ }^{7-13)}$

In these investigations, however, few attempt has been made to austenitize rapidly in a continuous annealing line after cold rolling for the high productivity. In the present study the applicability of a continuous annealing process to short-cycle austenitization of a cold rolled $18 \% \mathrm{Ni}$ maraging steel has been examined. The present study includes the texture formation in austenitization and the fine struc-

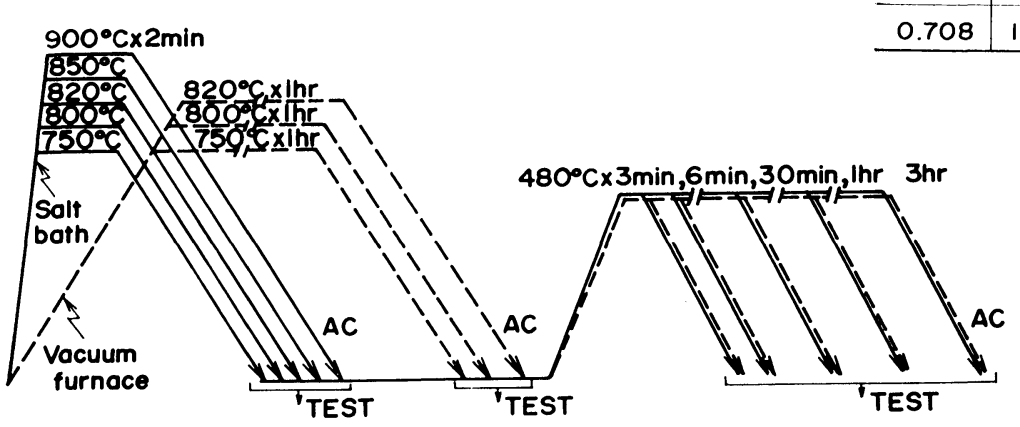

Fig. 1. Heat treatment sequence.

* Based on the paper presented to the 108th ISIJ Meeting, October 1984, S1282, at Hiroshima University in Hiroshima. Manuscript received on July 29, 1985; accepted in the final form on May 16, 1986. (C) 1986 ISIJ

** Fukuyama Research Laboratory, Technical Research Center, Nippon Kokan K.K., Kokan-cho, Fukuyama 721.

*** Technical Research Center, Nippon Kokan K.K., Minamiwatarida-cho, Kawasaki-ku, Kawasaki 210. tural change which causes a marked hardening in the early stage of aging.

\section{Experimental Procedures}

The chemical composition of a $18 \% \mathrm{Ni}$ maraging steel used in this study is shown in Table 1 . The starting material was prepared by melting a mixture of electrolytic iron and other high purity alloying metals in a high frequency vacuum induction furnace and by casting into a $50 \mathrm{~kg}$ ingot. The ingot was homogenized at $1200{ }^{\circ} \mathrm{C}$ for $10 \mathrm{~h}$ and hot rolled with three intermediate reheating treatments at $1100^{\circ} \mathrm{C}$ : the reduction in thickness was from 140 to $80 \mathrm{~mm}$ band was pickled, cold rolled to a thickness of $1.0 \mathrm{~mm}$ by a laboratory mill and heat treated in the proedure schematically shown in Fig. 1. Austenitizashort or long-cycle was simulated by heating the specimen in a salt bath or in a vacuum furnace followed by air cooling. The long-cycle austenitization was made at $820^{\circ} \mathrm{G}$ for $1 \mathrm{~h}$ according to the conventional condition for maraging steel. The subsequent aging was conducted at $480{ }^{\circ} \mathrm{C}$ for a period ranging from $3 \mathrm{~min}$ to $3 \mathrm{~h}$.

The effects of cold rolling and austenitizing condiThe the texture formation were studied in terms $\{100\}$ pole figures and the normalized relative values of integrated X-ray intensity of $110,200,112$, $310,222,321$ and 332 diffraction calculated by the ollowing equation ${ }^{14)}$ (hereafter, referred to as $p$ -

Table 1. Chemical composition of steel used. (wt $\%$ )

\begin{tabular}{c|c|c|c|c|c|c}
\hline $\mathrm{C}$ & $\mathrm{Si}$ & $\mathrm{Mn}$ & $\mathrm{P}$ & $\mathrm{S}$ & sol. Al & $\mathrm{N}$ \\
\hline 0.009 & $\mathrm{tr}$ & $\mathrm{tr}$ & $\mathrm{tr}$ & 0.001 & 0.004 & 0.0037 \\
\hline \hline $\mathrm{Ti}$ & $\mathrm{Ni}$ & $\mathrm{Co}$ & $\mathrm{Mo}$ & $\mathrm{Cr}$ & \multicolumn{2}{|c}{} \\
\hline 0.708 & 18.13 & 8.15 & 4.74 & 0.130 &
\end{tabular}




$$
p=\left(I_{h k l} / I_{h k l}^{\circ}\right) /(1 / n) \cdot \Sigma\left(I_{h k l} / I_{h k l}^{\circ}\right)
$$

where, $I_{h k l}^{\circ}$ : The theoretical relative intensity of $h k l$ diffraction from a randomly grain oriented specimen

$I_{h k l}$ : The measured intensity of $h k l$ diffraction

$n$ : The number of $h k l$ diffractions measured and used in the summation.

The mechanical properties of as-annealed samples were measured by tensile tests with a gage of $20 \mathrm{~mm}$ length and $12.5 \mathrm{~mm}$ width and bending tests with a gage of $100 \mathrm{~mm}$ length and $20 \mathrm{~mm}$ width. The precipitation hardening during aging were followed by the changes in the Rockwell hardness in $\mathrm{G}$ scale and in the electrical resistivity at $-196{ }^{\circ} \mathrm{C}$. Texture formation in austenitization was examined by the orientation distribution function (ODF) reconstructed from the $\{100\},\{110\}$ and $\{211\}$ pole figures. ${ }^{15)}$ Fine structural changes during aging were studied with the Mössbauer spectrometry of $\gamma$-rays from a ${ }^{57} \mathrm{Co}$ source.

\section{Results and Discussion}

\section{Formation of Cold Rolling Texture}

$\{100\}$ pole figures and $p$-values of the as-hot rolled band and the $78 \%$ cold rolled sheet are shown in Figs. 2 and 3, respectively. The microstructure of hot band was fully transformed into martensite at a temperature between 200 and $100{ }^{\circ} \mathrm{C}$ during cooling after hot rolling. Figure 2 shows development of a strong texture due to transformation from deformed prior austenite in the hot band. It is known that the texture of $\alpha^{\prime}$-phase transformed from deformed $\gamma$ was markedly influenced by the $\mathrm{Ni}$ content. ${ }^{16-18)}$ The pole figure of the hot band suggests a preferred orientation in $\{568\}\langle 421\rangle$ and is similar to that reported for the texture of martensite derived from deformed $\gamma$ in a $0.3 \% \mathrm{C}-12 \% \mathrm{Cr}-6 \% \mathrm{Ni}$-iron alloy. ${ }^{18)}$ Borik and Richman analysed the texture to be a transformation product from the deformed austenite having $\{110\}<225\rangle$ texture by the Kurdjumov-Sachs relationship. The $p$-values of $\{211\},\{332\}$ and $\{222\}$ are relatively high since the angles between these planes
As-hot rolled

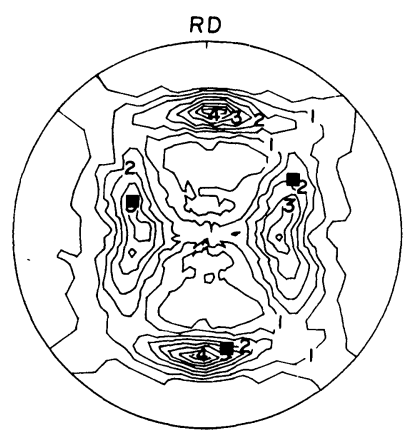

- $(568)(\overline{4} 21]$

\section{$78 \%$ Cold rolled}

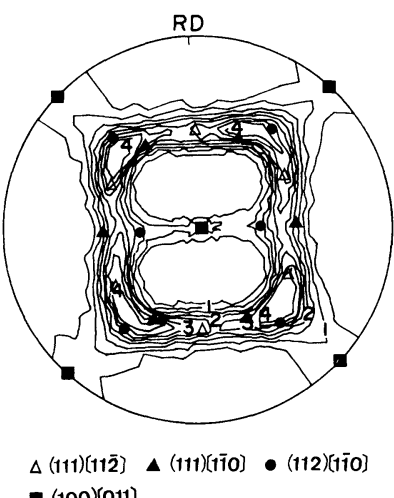

- (100)(011)

Fig. 2. $\{100\}$ pole figures of hot band and cold rolled sheet. and $\{568\}$ plane are less than 11.1 degrees in cubic crystal.

Cold rolling with a reduction of $78 \%$ develops the

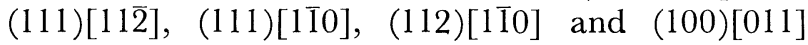
preferred orientations similar to the cold rolling texture of $\alpha$-iron, although the (111)[uvw] component is high as compared with the other orientations. Dickson and Gray ${ }^{19}$ have reported that the cold rolling texture was composed of the (001)[110] and (557)[110] components, with the (111)[112] component of lower intensity after $90 \%$ reduction. The difference from the results of the present authors in the intensity of the (001)[110] component is considered to be caused by the difference in the reduction rate. The (557)[110] component is the preferred orientation in transformation texture after austenitization as shown in the ODF analyses of Figs. 8 and 9.

The present results on $p$-values are different from those of Dickson ${ }^{19)}$ in the slight increase in $\{100\}$, the marked decrease in $\{211\}$ and the remaining of $\{332\}$ by cold rolling, however the decreases in $\{110\}$, $\{310\}$ and $\{321\}$, and the increase in $\{111\}$ are noticed in both results. This is probably caused by the difference in the original textures: the normalized hot band in Dickson's study and the as-hot rolled band in the present study.

\section{Textures and Mechanical Properties of Annealed Sheets}

Formability of the as-annealed sheet is important in a practical use of maraging steel since it becomes worse after aging. Accordingly, the goal of rapid annealing is to obtain formability no less than the level of products austenitized at $820^{\circ} \mathrm{G}$ for $1 \mathrm{~h}$. Because of the difficulty in measurement of the plastic strain anisotropy to assess the formability, the changes in texture were examined after short or long-cycle austenitization, as shown in Figs. 4 and 5 by the $\{100\}$ pole figures and $p$-values, respectively.

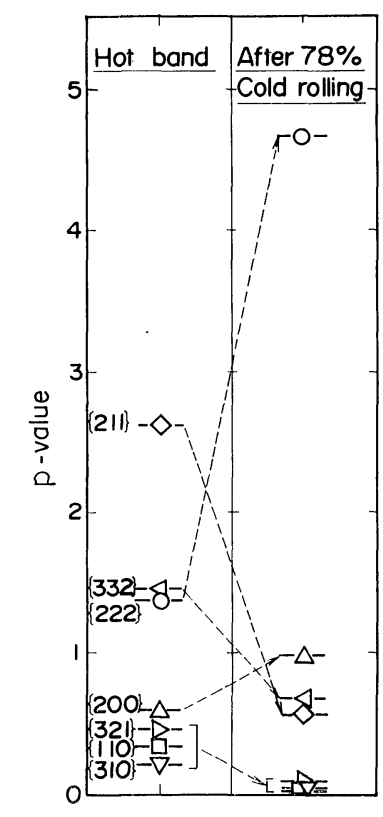

Fig. 3. Change in $p$-values with cold rolling. 


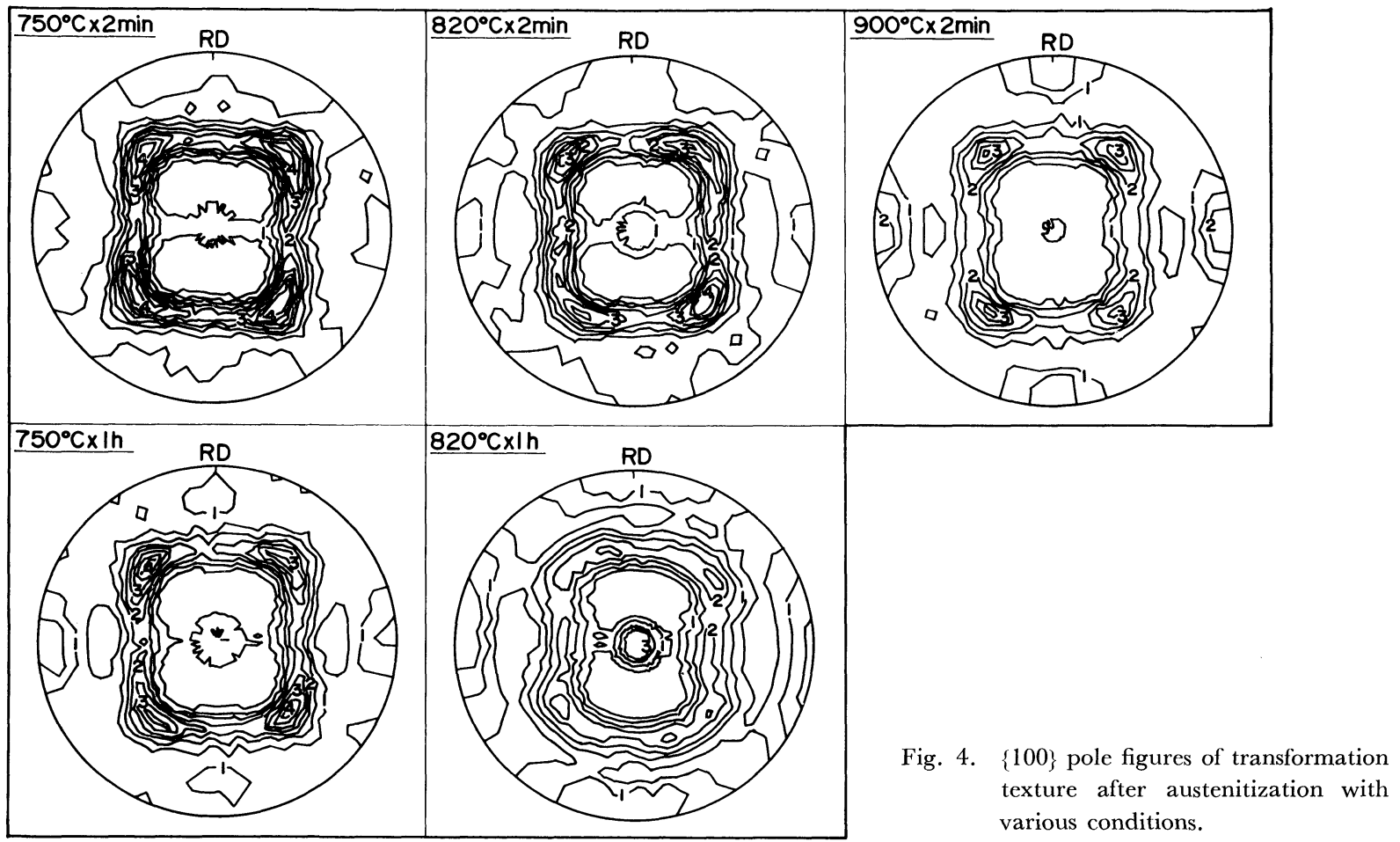

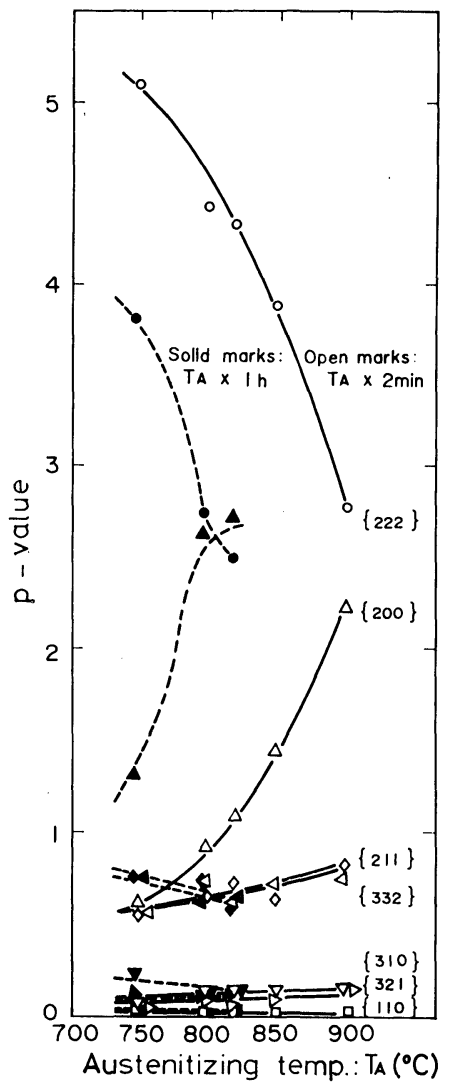

Fig. 5. Change in $p$-values with austenitization.

Higher austenitizing temperatures weaken the (111) [112] and (111)[110] orientations and strengthen the (100)[001] orientation. From a series of the changes in texture with austenitization, it is recognized that the texture transformed from a reverted austenite is different from that transformed from deformed austenite as shown in Fig. 2, and that the cold rolling texture is transmitted in the transformation texture formed during air cooling after austenitization. Rapid austenitizing at $900{ }^{\circ} \mathrm{C}$ for 2 min produces a texture intermediate of those austenitized at $750{ }^{\circ} \mathrm{C}$ and $820^{\circ} \mathrm{C}$ for $1 \mathrm{~h}$, which is consistent with the results of $p$-values given in Fig. 5.

The changes in mechanical properties after austenitization were estimated by tensile tests. The effect of austenitizing temperature on the strength and ductility of as-annealed samples are shown in Fig. 6. The ultimate tensile strength (TS) monotonously decreases with increasing temperatures for each types of annealing, while the $0.2 \%$ proof stress markedly decreases in the range from 800 to $850^{\circ} \mathrm{C}$. The influence of austenitizing temperature on the total elongation is small, thus the total elongation more than $10 \%$ is obtainable if the cold rolled steel sheet is austenitized at a temperature higher than $800{ }^{\circ} \mathrm{C}$. Little dependence of elongation on austenitizing condition is considered to be a consequence of a small content of harmful elements for ductility like carbon, phosphorus and sulfur in the steel. Differences in microstructure is not apparent between the martensite transformed from extensively and slightly recrystallized austenite, since the martensite transformation produces a high density of dislocations in the matrix.

For evaluation of practical use, bending tests were carried out with oblong specimens. The result is given in Fig. 7. Limit of the bending radius of the materials annealed at $750{ }^{\circ} \mathrm{C}$ without cracking is higher than $5 \mathrm{~mm}$ because of an insufficient recovery of ductility as shown in Fig. 6. Austenitization at a temperature higher than $820^{\circ} \mathrm{C}$ provides a bending radius less than $3 \mathrm{~mm}$ even by short-cycle processing.

The present results show that short-cycle annealing, which is practically processed in a continuous annealing line, can be applied to austenitization of cold 


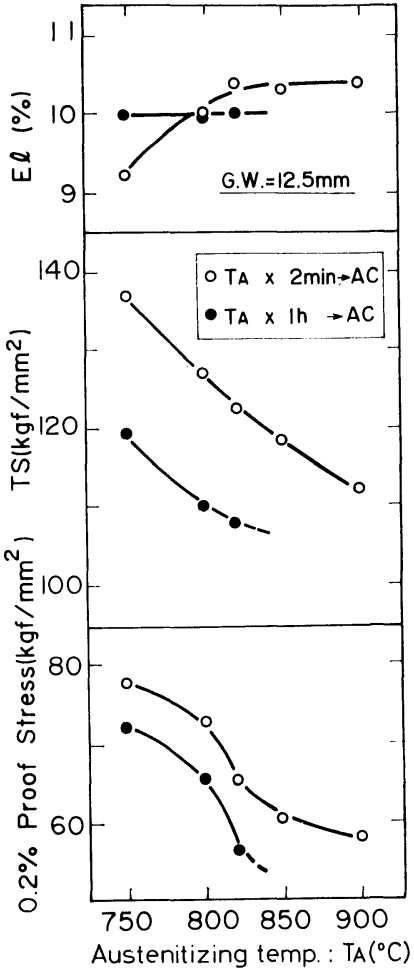

Fig. 6. Changes in tensile properties with austenitization. rolled maraging steel sheets provided that the heating temperature is about $900{ }^{\circ} \mathrm{C}$.

\section{Process of Texture Change in Austenitization}

In a maraging steel, shape memory phenomenon has been reported in a reversible $\alpha^{\prime} \rightarrow \gamma \rightarrow \alpha^{\prime}$. transformation. ${ }^{20)}$ Heredity of texture is also suggested in the present result that the deformation texture is retained after austenitization at a relatively high temperature, as shown in Fig. 4.

The texture changes in austenitization were studied

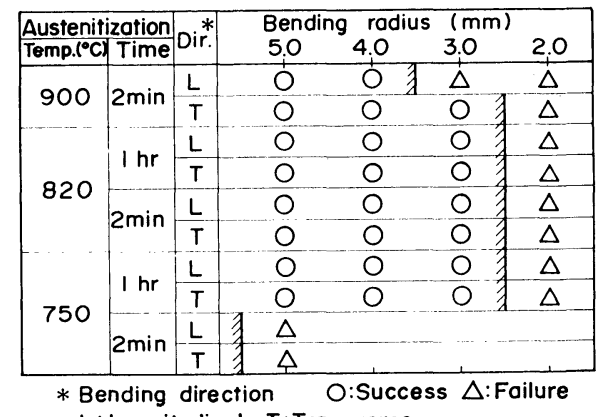

$\mathrm{L}$ : Longitudinal, $\mathrm{T}$ :Transverse

Fig. 7. Limits of bending radius of as-annealed samples. (Sample thickness: $1 \mathrm{~mm}$ )
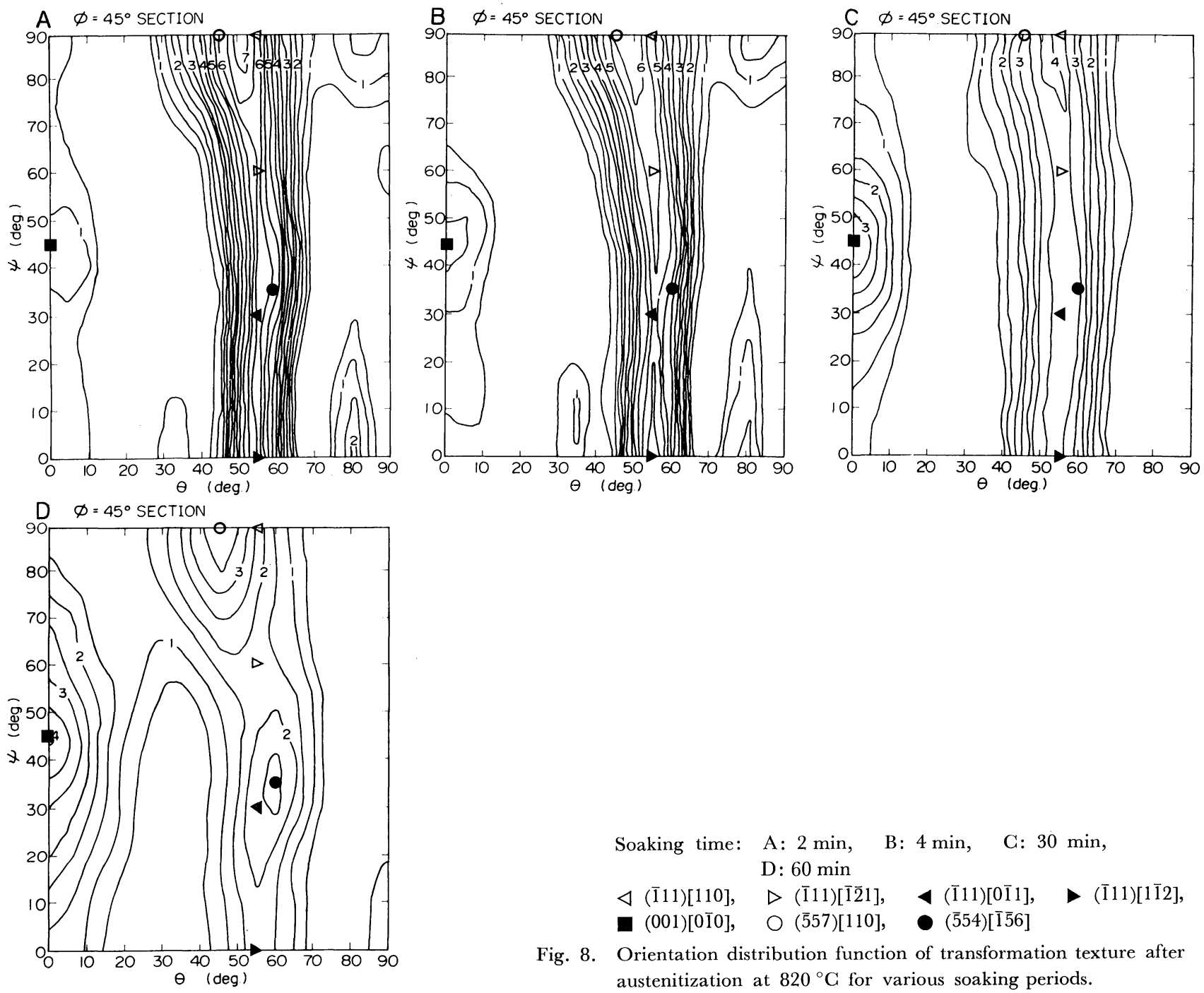
Soaking time: A: 2 min
B: $4 \mathrm{~min}$,
C: $30 \mathrm{~min}$,
D: $60 \mathrm{~min}$
$\triangleleft(\overline{1} 11)[110], \quad \triangleright(\overline{1} 11)[\overline{1} \overline{2} 1]$,
$(\overline{1} 11)[0 \overline{1} 1]$
$(\overline{5} 54)[\overline{1} \overline{5} 6]$
(111) [1] 12$]$
(001)[010], $\bigcirc(\overline{5} 57)[110]$,

Fig. 8. Orientation distribution function of transformation texture after austenitization at $820^{\circ} \mathrm{C}$ for various soaking periods. 
by measurements of the transformation textures after austenitization at 820 and $900^{\circ} \mathrm{C}$. Figure 8 shows the $\phi=45 \mathrm{deg}$ section of orientation distribution functions $^{21)}$ reconstructed from the pole figures of $\{100\}$, $\{110\}$ and $\{211\}$ measured after austenitization at $820^{\circ} \mathrm{C}$. A strong texture having an $\langle 111\rangle$ fiber parallel to the normal direction (ND), which has developed during cold rolling, is retained after $2 \mathrm{~min}$. Soaking at $820^{\circ} \mathrm{C}$ tends to strengthen the (001)[0]0] orientation in place of the $\langle 111\rangle$ fiber component, and the (557)[110] and (554) $[\overline{1} \overline{5} 6]$ orientations gradually develop.

Consequently, the transformation texture after austenitization at $820^{\circ} \mathrm{C}$ for $1 \mathrm{~h}$ followed by air cooling consists of the components oriented nearly in

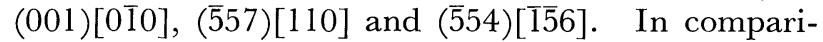
son with the transformation texture after austenitization consisting mainly of (557) [110] and $\sim(510)$ [150] components reported by Dickson and Gray, ${ }^{19)}$ development in the (001)[010] component is observed in this investigation. The slight deviation of the (001)[0 $\overline{1} 0]$ component from the (510)[150] component ${ }^{19)}$ in the transformation texture is caused by the change in the variant selectivity in $\gamma \rightarrow \alpha^{\prime}$ transformation due to the differences in the reduction rate, the cold rolling texture and the austenitizing condition.

Figure 9 shows the results of rapid annealing at $900{ }^{\circ} \mathrm{C}$, being substantially identical to Fig. 8 in spite of the difference in soaking temperature. Since reversible $\alpha^{\prime} \rightarrow \gamma \rightarrow \alpha^{\prime}$ transformation occurs even if the original $\alpha^{\prime}$ is deformed or the austenitizing temperature is varied to some extent, ${ }^{20}$ the changes in texture are considered to be caused by a gradual change of the variants operating in $\gamma \rightarrow \alpha^{\prime}$ transformation through refinement of reverted austenite grains by recrystallization.

The (001)[010] orientation is considered to be produced from fine austenite grains nucleated inside prior austenite grains as mentioned by Maki et al., ${ }^{20}$ ) not from the reverted austenite transformed from deformed $\alpha^{\prime}$ of $\{111\}\langle u v w\rangle$ orientations. Therefore an increase in (001)[0I0] orientation with soaking at $900{ }^{\circ} \mathrm{C}$ is probably caused by growth of fine austenite grains as well as the change in the variants in martensite transformation.

\section{Effects of Austenitizing Condition on Hardening during Aging}

The changes in hardness and electrical resistivity of the as-annealed sheets and the as-hot rolled band are shown with reference to the values before aging in Fig. 10. Marked hardness increase about $40 \%$ arises within aging for $3 \mathrm{~min}$ at $480{ }^{\circ} \mathrm{C}$. A longer aging brings a further increase in hardness, however, the hardening rate is reduced. With respect to the hardening of the as-hot rolled band and the cold rolled sheets after long-cycle annealing, the hardening rates are relatively high in the aging period between 30 and $60 \mathrm{~min}$. Electrical resistivity decreases proportionally in logarithmic scale with aging up to about $30 \mathrm{~min}$. Aging longer than 30 min causes a marked decrease in electrical resistivity. This is considered to be caused by an extensive precipitation of intermetallic compounds which bring about high hardening rate at the period of aging longer than $30 \mathrm{~min}$.

The rate of decrease in electrical resistivity and that of increase in hardness are compared in Fig. 11. It is apparent that the hardening rate is in linear correlation with the logarithmic rate of decreasing in electrical resistivity. The gradient varies in the range between 21.0 and 7.6, being maximum for extensive and minimum for brief austenitization. Lack of hardening accompanied by decrease in electrical resistivity in an incompletely austenitized specimen suggests that effective hardening can not be achieved because of reduction in hardenability due to a change in size and dispersion of precipitates. Autsenitization at $900{ }^{\circ} \mathrm{C}$ for $2 \mathrm{~min}$, which is adoptable in continuous annealing lines, produces larger rate of hardness increase in contrast to decrease in electrical resistivity
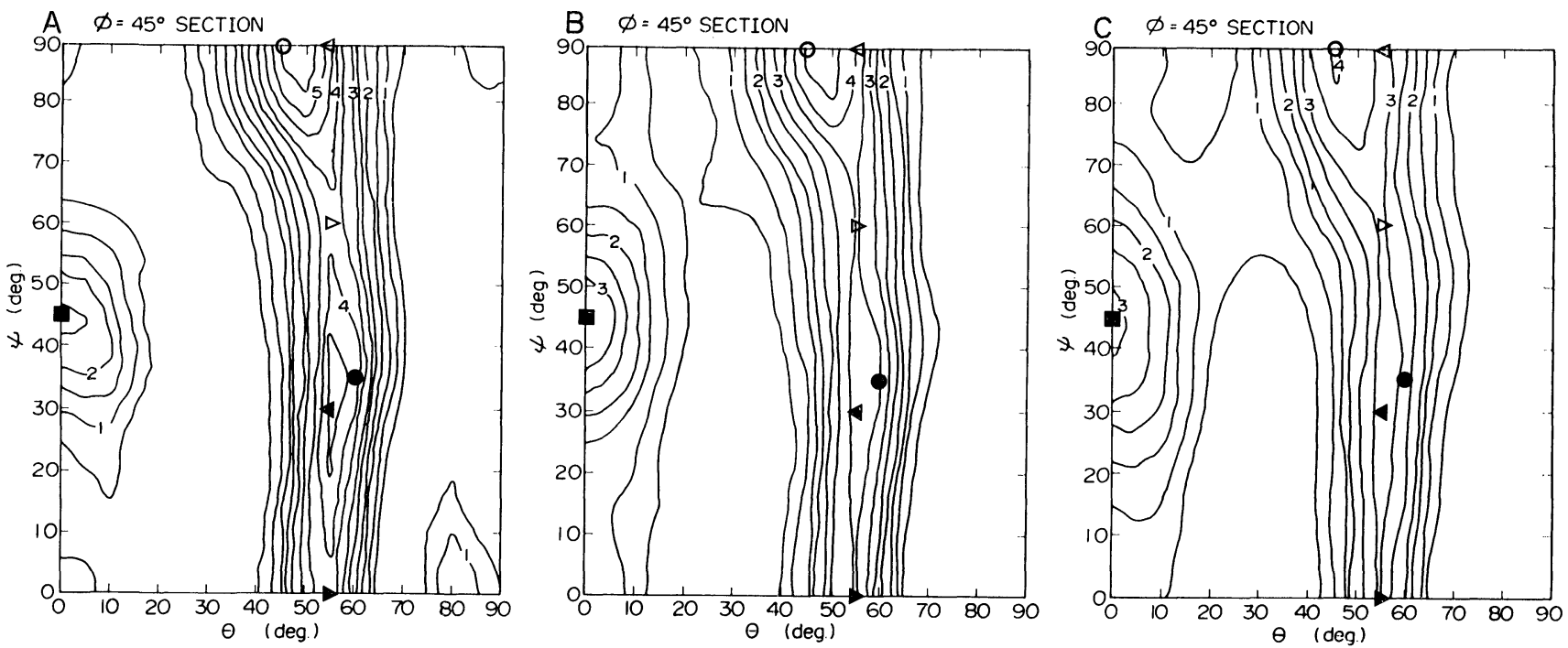

Soaking time: A: $1 \mathrm{~min}, \quad$ B: $2 \mathrm{~min}, \quad \mathrm{C}: 4 \mathrm{~min}$ $\triangleleft(\overline{1} 11)[110], \quad \triangleright(\overline{1} 11)[\overline{1} \overline{2} 1], \quad \triangleleft(\overline{1} 11)[0 \overline{1} 1], \quad \triangleright(\overline{1} 11)[1 \overline{1} 2]$,

Fig. 9. Orientation distribution function of transformation texture after austenitization at $900{ }^{\circ} \mathrm{C}$ for various soaking periods. 


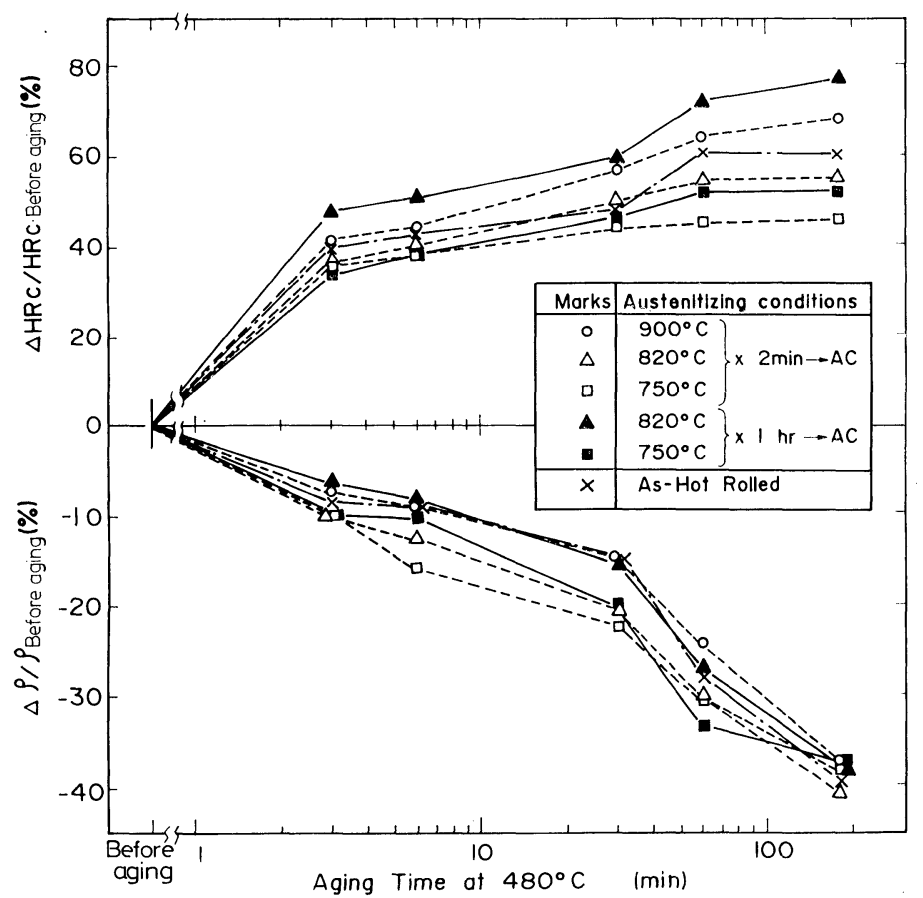

Fig. 10. Change in hardness (Rockwell C-scale) and electrical resistivity during aging at $480^{\circ} \mathrm{C}$.

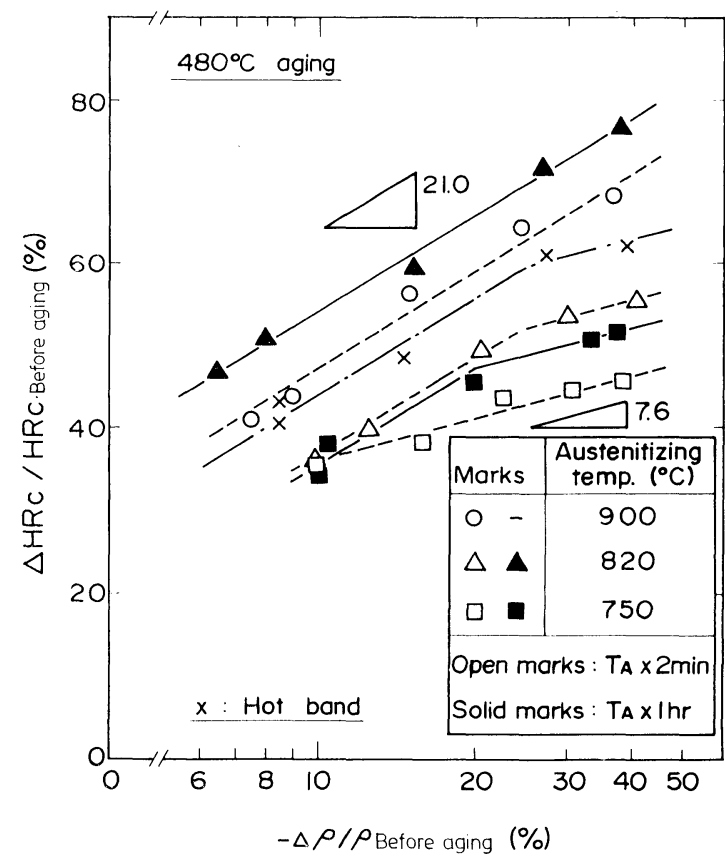

Fig. 11. Correlation between the rates of change in hardness and in electrical resistivity during aging at $480^{\circ} \mathrm{C}$. than the as-hot rolled state. The rate is close to that austenitized by the conventional condition of $820^{\circ} \mathrm{C}$ $\times 1 \mathrm{~h}$.

Activation energy for precipitation of intermetallic compounds was determined using the samples austenitized at $900{ }^{\circ} \mathrm{C}$ for $2 \mathrm{~min}$. Figure 12 shows the changes in electrical resistivity during aging at 460 , 480 and $500{ }^{\circ} \mathrm{C}$, and the Arrhenius' plots for the estimated precipitation rates of $\Delta \rho=-5$ and $-10 \mu \Omega \cdot \mathrm{cm}$. The value of activation energy was obtained as 68.5 and $78.1 \mathrm{kcal} / \mathrm{mol}$ from each slope of the Arrhenius' plots. These are nearly equal to the activation energy of volume diffusion of Mo in ferromagnetic $\alpha-\mathrm{Fe}$ $(68.0 \mathrm{kcal} / \mathrm{mol}),{ }^{22)}$ while the activation energy of $30 \sim$ $40 \mathrm{kcal} / \mathrm{mol}$ has been reported ${ }^{7,23,24)}$ for precipitation in maraging steels.

\section{Structural Change in the Early Stage of Aging}

The remarkable and rapid hardening during aging at about $480{ }^{\circ} \mathrm{C}$ observed in maraging steels have stimulated the studies on precipitation and crystal structures of precipitates by means of electrical resistivity measurements, ${ }^{10,11,13)}$ specific heat measurement ${ }^{12)}$ and electron microscopic observations. ${ }^{25,26)}$ Structural change in the early stage of aging leading to a marked hardening has not been extensively studied, although the formation of Mo rich clusters has been predicted. ${ }^{7,11)}$ So far the small-angle X-ray scattering ${ }^{27)}$ and the Mössbauer spectroscopy ${ }^{28,29)}$ have been applied only to the samples aged more than an hour. The present investigation was intended to find an atomic scale structural change in the early stage of aging by the Mössbauer spectrometry.

Figures 13 and 14 show the changes in the Mössbauer spectra with aging in the samples austenitized $820^{\circ} \mathrm{C} \times 1 \mathrm{~h}$ and $900{ }^{\circ} \mathrm{C} \times 2 \mathrm{~min}$, respectively. Sharp

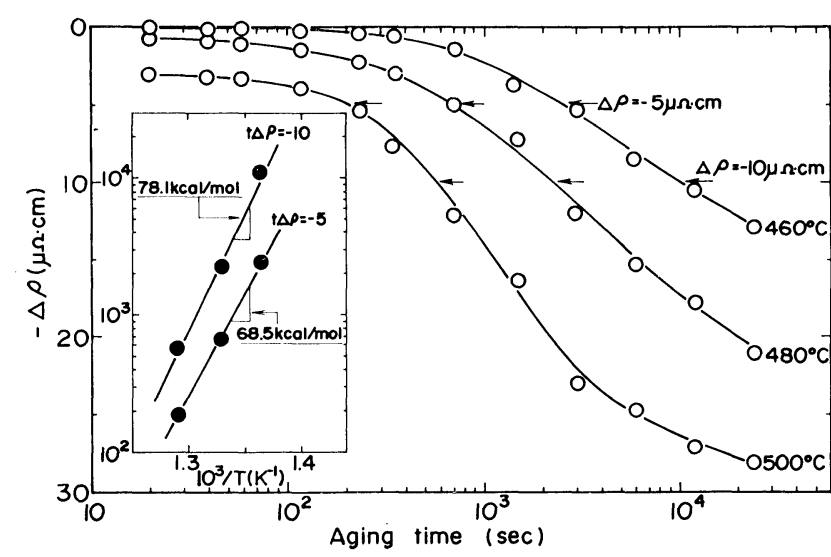

Fi.g 12. Change in electrical resistivity with aging at $460{ }^{\circ} \mathrm{C}, 480^{\circ} \mathrm{C}$ and $500^{\circ} \mathrm{C}$, and the Arrhenius plots for estimation of the activation energy for precipitation of intermetallic compounds.

six-peak spectra corresponding to the ferromagnetic phases are observed in both specimens together with the sub-peaks which are considered to be corresponding to $\mathrm{Fe}$ atoms with Mo environments, judging from a decrease in the hyperfine field compared with that observed in pure $\mathrm{Fe}^{30,31)} \mathrm{A}$ decrease in absorption in the sub-peaks after aging for $3 \mathrm{~min}$ at $480^{\circ} \mathrm{C}$ suggests the formation of Mo clusters or intermetallic compounds composed of Mo and other alloying elements in the early stage of aging. After aging at $480^{\circ} \mathrm{C}$ for $3 \mathrm{~h}$, the sub-peaks decrease sharply and a paramagnetic peak of intermetallic compounds is apparent in the center of the spectra.

A paramagnetic peak corresponding to existence of retained austenite is also observed besides the ferromagnetic peaks in the sample austenitized briefly at 
$900^{\circ} \mathrm{C}$. However, the retained $\gamma$ peak soon disappears with aging for $3 \mathrm{~min}$ at $480^{\circ} \mathrm{C}$, probably by $\gamma \rightarrow \alpha^{\prime}$ transformation due to the aging. An increase in internal stress due to a change in the atomic con-

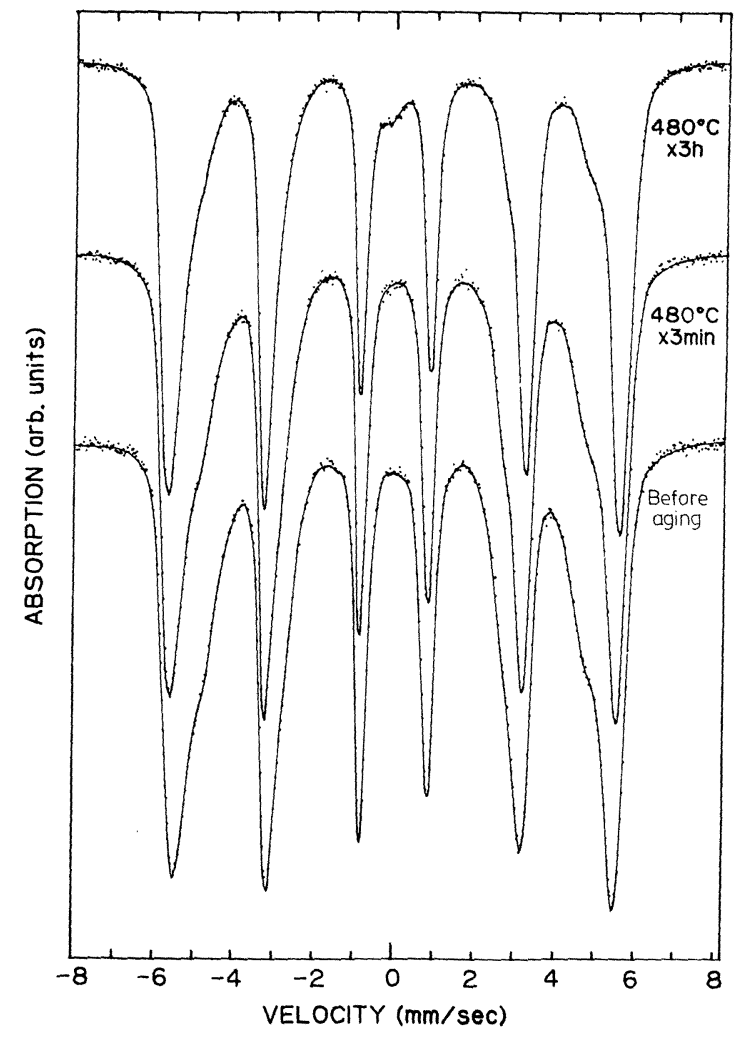

Fig. 13. Change in Mössbauer spectra with aging at $480^{\circ} \mathrm{C}$ after austenitization, $820^{\circ} \mathrm{C} \times 1 \mathrm{~h}$.

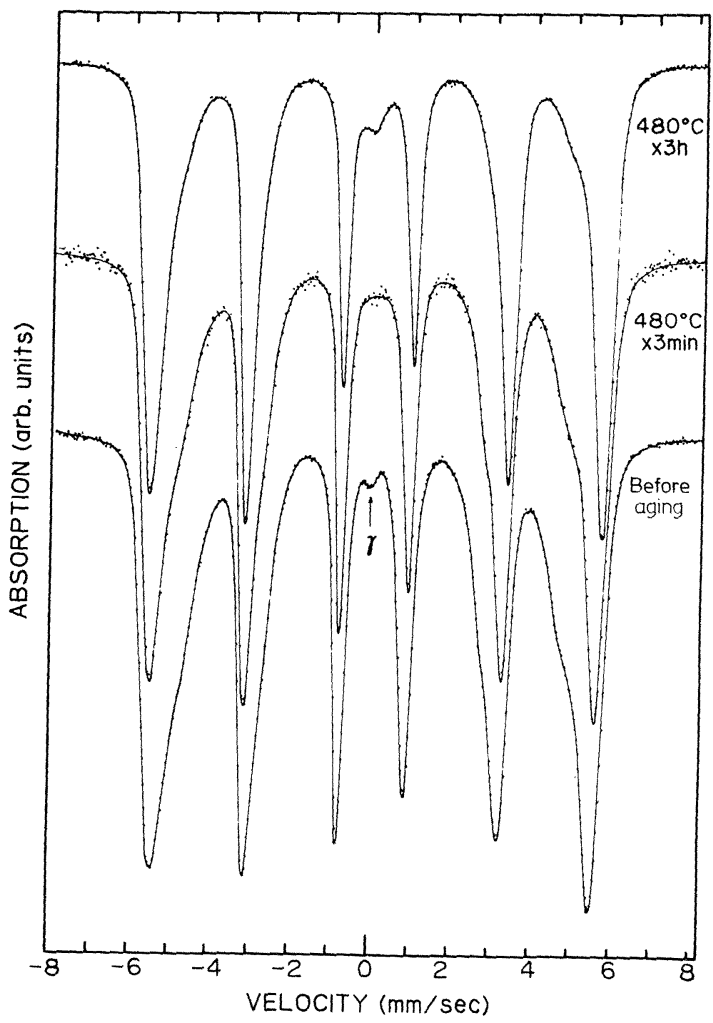

Fig. 14. Change in Mössbauer spectra with aging at $480^{\circ} \mathrm{C}$ after austenitization, $900^{\circ} \mathrm{C} \times 2 \mathrm{~min}$. figurations with aging prepares the most probable driving force for the $\gamma \rightarrow \alpha^{\prime}$ transformation. The retained $\gamma$ is thought to be finely dispersed. with the fine Widmanstätten morphology as reported by Peters, ${ }^{32}$ ) because the retained $\gamma$, thermally stable in the $\gamma \rightarrow \alpha^{\prime}$ transformation during air cooling, was transformed into $\alpha^{\prime}$ with beginning of the structural change in the early stage of aging.

The changes in fine structure during aging were followed quantitatively by the analysis of Mössbauer spectra reconstructed by the method of least square, the computing program of which has been originally developed in combination of the Simplex method and the Powell's method for least square. It includes the parameters on the hyperfine field, the peak height ratio, the half band width ratio and the quadrupole effect in the ferromagnetic line profiles to be composed of three types of the interaction peaks: Fe atoms with $\mathrm{Ni}$ neighbors (peak-1), with Fe neighbors (peak-2) and with Mo neighbors (peak-3). The conventional Mössbauer studies of maraging steel have not used such an analysis because it is difficult to estimate the complex interaction of the alloying elements.

The changes in the decomposed spectra during aging for the samples austenitized at $900{ }^{\circ} \mathrm{C}$ for $2 \mathrm{~min}$ are shown in Fig. 15. The reconstructed spectra from the three types of peaks show fairly a good agreement with the measured spectra.

The changes in the volume fractions of ferromagnetic phases interacted with $\mathrm{Mo}$ and $\mathrm{Ni}$ neighbors and paramagnetic phases of retained $\gamma$ and intermetallic compounds are shown in Fig. 16. The decrease in Mo neighbors in the early stage of aging suggests the formation of Mo clusters which probably causes an increase in internal stress as mentioned above. A smaller change in $\mathrm{Ni}$ neighbors as compared with a large decrease in Mo neighbors in the early stage of aging and the lack of the paramagnetic peak in the early stage of aging suggests the formation of Mo atom clustering instead of the precipitation of weakly ferromagnetic $\mathrm{Ni}_{3} \mathrm{Mo}$ as predicted by Marcus et al. ${ }^{28)}$

Consequently the marked hardening in the early stage of aging is considered to arise from lattice distortion due to the clustering of Mo atoms which is likely to proceed not only favorably in the elastic stress fields around dislocations ${ }^{10)}$ but also uniformly in the matrix by the stress induced $\gamma \rightarrow \alpha^{\prime}$ transformation in the early stage of aging.

\section{Conclusion}

The applicability of a continuous annealing process to short-cycle austenitization of a cold rolled $18 \%$ $\mathrm{Ni}$ maraging steel sheet has been examined by the changes in the mechanical properties in the asaustenitized conditions, the texture formation in cold rolling and austenitizing with long and short-cycle conditions and the fine structural change during aging. The conclusions are summarized as follows.

(1) In $18 \% \mathrm{Ni}$ maraging steel, cold rolling with a reductions of $78 \%$, develops the (111)[112]], (111) [1I0], (112)[1T0] and (100)[011] preferred orientations similar to the cold rolling texture of $\alpha$-iron, 


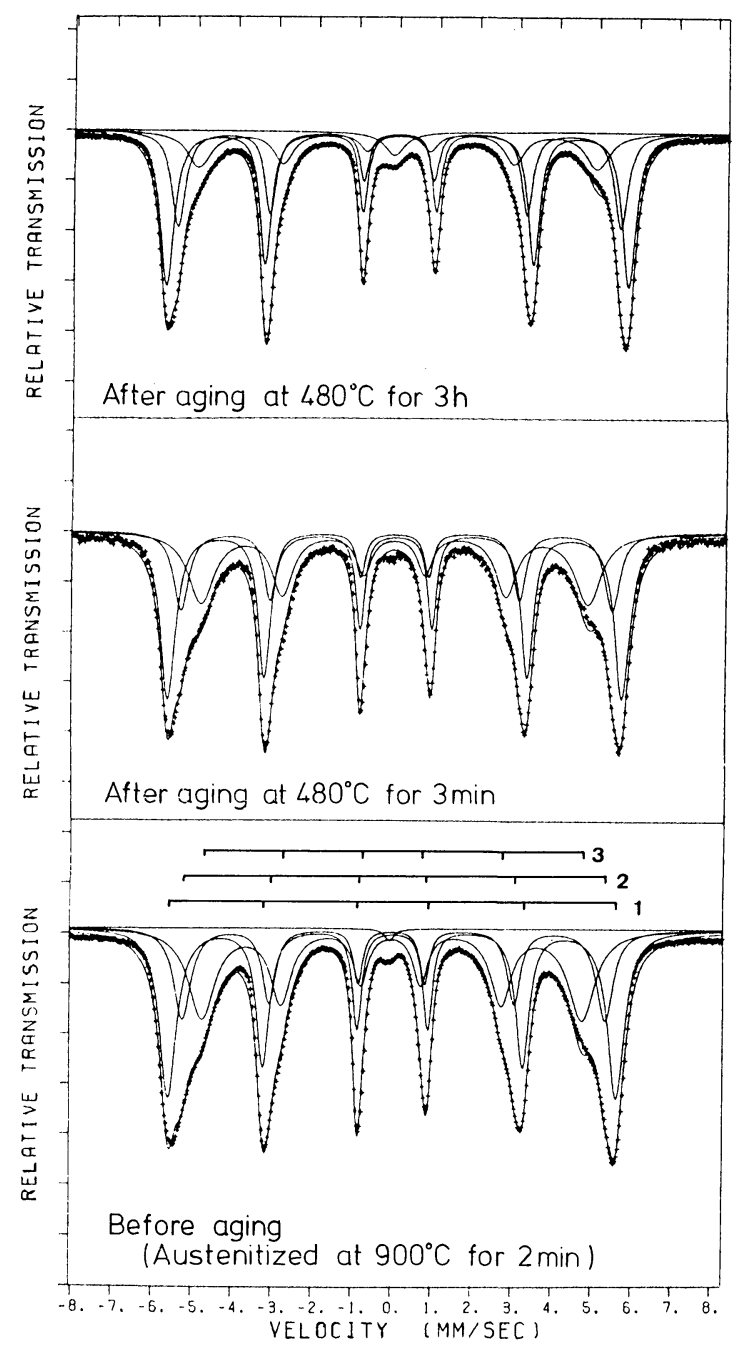

Fig. 15. Comparison between the spectra reconstructed from three types of peaks of different environments and the measured spectra given in Fig. 14.

although the (111)[uvw] component is high as compared with the other orientations.

(2) The cold rolling texture composed of high density of $\{111\}\langle u v w\rangle$ orientation is strongly transmitted in the trasformation texture formed after rapid austenitization. And with the progress of austenitization, the near $(\overline{5} 57)[110]$ and $(\overline{5} 54)[\overline{1} 56]$ orientations develop from the $\{111\}\langle u v w\rangle$ orientation and the (001) [0Ī0] orientation appears.

(3) In spite of a slight difference in the texture, austenitization of the cold rolled $18 \% \mathrm{Ni}$ maraging steel can be performed in a continuous annealing line to provide the mechanical property comparable to that obtained in the conventional austenitizing condition of $820^{\circ} \mathrm{C} \times 1 \mathrm{~h}$ if that the austenitizing temperature is higher than $900^{\circ} \mathrm{C}$.

(4) A marked hardness increase of about $40 \%$ from the as-annealed state is observed in the early stage of aging at $480{ }^{\circ} \mathrm{C}$ simultaneously with a decrease in electrical resistivity. While the extensive austenitization causes an increase in the hardening rate in comparison with the decreasing rate of electrical resistivity, a hardening rate comparable to the conventional austenitizing conditions of $820^{\circ} \mathrm{C} \times 1 \mathrm{~h}$ is

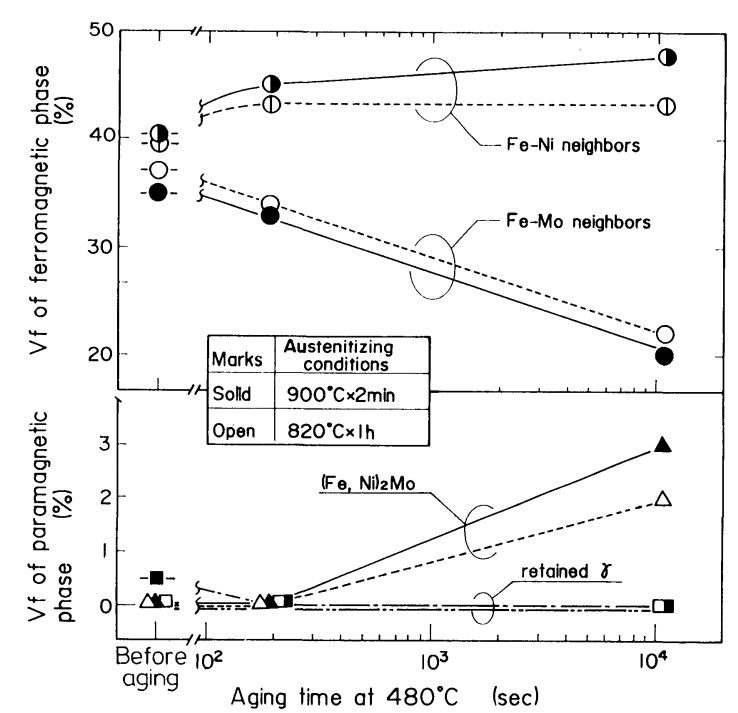

Fig. 16. Change in the volume fraction $(V f)$ of ferromagnetic phases and paramagnetic phases during aging at $480^{\circ} \mathrm{C}$.

obtainable in the short-cycle austenitization of $900{ }^{\circ} \mathrm{C}$ $\times 2$ min.

(5) Within 3 min of aging at $480^{\circ} \mathrm{C}$, a decrease in the number of $\mathrm{Fe}$ atoms with Mo neighbors was clearly observed by Mössbauer spectrometry. Consequently, both the marked hardening from the asaustenitized condition and the disappearance of retained $r$ which was observed in the short-cycle austenitizing condition in the early stage of aging are suggested to be a result of lattice distortion by clustering of Mo atoms.

\section{REFERENGES}

1) R. F. Decker, J. T. Eash and A. J. Goldman: Trans. ASM, 55 (1962), 58.

2) W. R. Patterson and L. S. Richardson: Trans. ASM, 59 (1966), 71.

3) G. P. Contractor: J. Metals, 18 (1966), 938.

4) G. W. Tuffnell and R. L. Cairns: Trans. ASM, 61 (1968), 798.

5) Y. Kawabe: Bull. Japan Inst. Metals, 14 (1975), 767.

6) H. Soeno: Bull. Japan Inst. Metals, 20 (1981), 928.

7) D. T. Peters and G. R. Gupp: Trans. Met. Soc. AIME, 236 (1966), 1420.

8) S. Floreen: Met. Rev., 126 (1968), 115.

9) G. R. Speich: Trans. Met. Soc. AIME, 245 (1969), 2553.

10) H. Soeno and T. Kuroda: Tetsu-to-Hagané, 55 (1969), 137.

11) H. Soeno: J. Japan Inst. Metals, 39 (1975), 528.

12) Y. Tokunaga and S. Takaki: Bull. Japan Inst. Metals, 21 (1982), 234.

13) Y. Asayama: J. Japan Inst. Metals, 48 (1984), 122.

14) M. H. Mueller, W. P. Chernock and P. A. Beck: Trans. Met. Soc. AIME, 212 (1958), 39.

15) R. J. Roe: J. Appl. Phys., 36 (1965), 2024.

H. J. Bunge: Zeit. Metallk., 56 (1965), 872.

16) H. Abe, K. Ito and R. Fukumoto: J. Japan Inst. Metals, 31 (1967), 37.

17) H. Abe and K. Ito: J. Japan Inst. Metals, 31 (1967), 1300.

18) F. Borik and R. H. Richman: Trans. Met. Soc. AIME, 239 (1967), 675.

19) M. J. Dickson and S. D. Gray: J. Appl. Cryst., 4 (1971), 
452.

20) T. Maki, H. Morimoto and I. Tamura: Tetsu-to-Hagané, 65 (1979), 1598.

21) G. J. Davies, D. J. Goodwill and J. S. Kallend: J. Appl. Cryst., 4 (1971), 67.

22) L. G. Schulz: J. Appl. Phys., 20 (1949), 1030.

23) S. Floreen and D. F. Decker: Trans. ASM, 55 (1962), 518.

24) K. Detert: Arch. Eisenhüttenw., 37 (1966), 579.

25) M. Fukamachi, Y. Kawabe, K. Nakazawa and S. Muneki: J. Japan Inst. Metals, 47 (1983), 237.

26) Y. Okada, J. Endo and T. Nakayama: Tetsu-to-Hagané, 69 (1983), 703.
27) G. Servant, G. Maeder and G. Cizeron: Met. Trans., 6A (1975), 981.

28) H. Marcus, L. H. Schwartz and M. F. Fine: Trans. ASM, 59 (1966), 468.

29) J. M. Genin, G. Le Caer, P. Maitrepierre and B. J. Thomas: Scripta Met., 8 (1974), 15.

30) G. E. Johnson, M. S. Ridout and T. E. Cranshaw: Proc. Phys. Soc., 81 (1963), 1079.

31) W. E. Saver and R. J. Reynik: J. Appl. Phys., 42 (1971), 1604.

32) D. T. Peters: Trans. ASM, 61 (1968), 62. 